\title{
Biocompatibility and tissue regenerating capacity of crosslinked dermal sheep collagen
}

\author{
P. B. van Wachem, ${ }^{1, *}$ M. J. A. van Luyn, ${ }^{1}$ L. H. H. Olde Damink, ${ }^{2}$ P. J. Dijkstra ${ }_{r}^{2}$ J. Feijen, $^{2}$ and P. Nieuwenhuis ${ }^{1}$ \\ ${ }^{1}$ Department of Histology and Cell Biology, Section Biomaterials Research, University of Groningen, Oostersingel \\ 69/2, 9713 EZ Groningen, The Netherlands; ${ }^{2}$ Department of Chemical Technology, University of Twente, P.O. \\ Box 217, 7500 AE Enschede, The Netherlands
}

The biocompatibility and tissue regenerating capacity of four crosslinked dermal sheep collagens (DSC) was studied. In vitro, the four DSC versions were found to be noncytotoxic or very low in cytoxicity. After subcutaneous implantation in rats, hexamethylenediisocyanatecrosslinked DSC (HDSC) seldom induced an increased infiltration of neutrophils or macrophages, as compared with normal wound healing; whereas new formation of collagen was observed. DSC crosslinked with glutaraldehyde (GDSC) followed by reaction with $\mathrm{NaBH}_{4}$ shortly after implantation showed an increased infiltration of neutrophils with a deviant morphology. Furthermore, a high incidence of calcification was observed, which may explain the minor ingrowth of giant cells and fibroblasts, and the poor formation of new rat collagen. Acyl azide-crosslinked DSC (AaDSC) first induced an increased infiltration of macrophages, and then of giant cells, both with high lipid formation. AaDSC degraded at least twice as slowly as HDSC and GDSC, finally leaving a matrix of newly formed rat collagen. Samples crosslinked with 1-ethyl-3-(3dimethylaminopropyl)carbodiimide hydrochloride and $N$-hydroxysuccinimide (ENDSC) induced the same mild cellular reaction as HDSC; whereas, similar to AaDSC, the degradation rate was slow and an optimal rat collagen matrix was formed. Of the crosslinked DSC samples, ENDSC seems most promising for tissue regeneration. (c) 1994 John Wiley \& Sons, Inc.

\section{INTRODUCTION}

Various collagen-based materials have been used in the biomedical field for applications such as abdominal wall repair ${ }^{1,2}$ and tendon, ${ }^{3}$ ligament, ${ }^{4,5}$ and blood vessel replacement. ${ }^{6,7}$ Although the tissue interactions with collagen-based materials have been extensively studied ${ }^{8-10}$ the possible tissue-regenerating capacity of these materials has not been reported in the literature. Collagen-based biomaterials may be used as temporary scaffolds for tissue regeneration, provided that the materials are biocompatible, i.e., noncytotoxic, and that they induce the formation of new host collagen.

Our group previously studied commercially available dermal sheep collagens (DSC). ${ }^{11-17}$ In vitro cytotoxicity studies ${ }^{11-14}$ were performed using the methylcellulose (MC) cell culture with human skin fibroblasts. ${ }^{11}$ The cytotoxicity of noncrosslinked DSC (NDSC) was low. These samples did not induce changes in cell morphology, and resulted in a cell

*To whom correspondence should be addressed. growth inhibition of only $20 \%$. Both commercially available hexamethylenediisocyanate (HMDIC)-crosslinked HDSC and glutaraldehyde (GA)-crosslinked DSC (GDSC) were found to be cytotoxic. HDSC inhibited cell growth by $50 \%$ and induced moderate lipid degeneration of cells. GDSC was highly cytotoxic, with $80 \%$ cell growth inhibition and lipid degeneration. ${ }^{11-14}$

The cytotoxicity of the crosslinked samples was confirmed by subcutaneous implantations in rats. ${ }^{15-17} \mathrm{Al}$ though NDSC was seldom infiltrated by neutrophils or macrophages, HDSC samples were infiltrated by increased numbers of neutrophils and macrophages during the first 10 days after implantation. Locally, the neutrophils showed a deviant morphology, i.e., the cytoplasm and organelles appeared to have disintegrated. Furthermore, a high incidence of lipid formation was observed. With GDSC, extensive lipid formation, cell degeneration, and cell death, all reflecting its high cytotoxicity, were observed. ${ }^{16}$

Because both HDSC and GDSC had fast degradation rates (15 weeks), ${ }^{15,16}$ and to overcome the cytotoxic problems associated with the use of HDSC 
and GDSC, both HMDIC ${ }^{18,19}$ and GA crosslinking ${ }^{18,20}$ have been studied in more detail and optimized. Furthermore, the applicability of the acyl azide method (AaDSC) was studied, ${ }^{21}$ and a new crosslinking method based on the use of a mixture of the water soluble carbodiimide 1-ethyl-3-(3-dimethyl aminopropyl)-carbodiimide hydrochloride (EDC) and $N$-hydroxysuccinimide (NHS), resulting in ENDSC, was developed. ${ }^{22}$

In the present study, the biocompatibility of optimized HDSC and GDSC, and of newly crosslinked AaDSC and ENDSC was studied in vitro using $\mathrm{MC}$ cell culture, and in vivo during subcutaneous implantation in rats for periods up to 30 weeks. With the in vivo study, emphasis was put on both the biocompatibility and the tissue regenerating capacity.

\section{MATERIALS AND METHODS}

\section{Materials}

Noncrosslinked dermal sheep collagen (NDSC) processed from sheep skin $^{23}$ was obtained from the Zuid Nederlandse Zeemlederfabriek (Oosterhout, The Netherlands). NDSC was washed 4 times with distilled water, 2 times with acetone, and again 2 times with distilled water. Thereafter, the material was frozen and lyophilized, followed by four different crosslinking methods.

Two methods were optimized versions of the commercial crosslinking methods with bifunctional agents, i.e., HMDIC and GA.

HMDIC crosslinking ${ }^{18,19}$

One-gram samples were crosslinked in $100 \mathrm{ml}$ phosphate buffer $\left(0.07 \mathrm{M} \mathrm{NaH} \mathrm{PO}_{4}, \mathrm{pH} 9.5\right)$ containing $1.5 \%(w / w)$ HMDIC (z.S., Merck-Schuchardt, Hohenbrunn, FRG) and $1.0 \%(\mathrm{w} / \mathrm{w})$ Tween 80 (z.S., MerckSchuchardt) as a surfactant for $5 \mathrm{~h}$ at room temperature. After crosslinking, the samples were rinsed for $30 \mathrm{~min}$ under a running tap, washed 2 times for $30 \mathrm{~min}$ with $4 \mathrm{M} \mathrm{NaCl}$, and 4 times for $30 \mathrm{~min}$ with distilled water to remove unreacted HMDIC or surfactant before lyophilization. The resulting DSC is hereafter referred to as HDSC.

\section{GA crosslinking ${ }^{20}$}

This method was performed by immersing 1-g samples in $100 \mathrm{~mL}$ phosphate buffer $\left(0.054 \mathrm{M} \mathrm{Na}_{2} \mathrm{HPO}_{4}\right.$, $\left.0.013 \mathrm{M} \mathrm{NaH}_{2} \mathrm{PO}_{4}, \mathrm{pH} 7.4\right)$ containing $0.5 \%(\mathrm{w} / \mathrm{w}) \mathrm{pu}-$ rified GA for $1 \mathrm{~h}$ at room temperature. Directly after crosslinking, samples were immersed in a freshly prepared $1.2 \mathrm{mg} / \mathrm{ml}$ solution of $\mathrm{NaBH}_{4}$ (Janssen Chimica, Beerse, Belgium) in phosphate buffer ( $\mathrm{pH}$ 7.4) for
$1 \mathrm{~h}$ to reduce unstable compounds. Thereafter, the samples were rinsed for $30 \mathrm{~min}$ under a running tap, washed 2 times for $30 \mathrm{~min}$ with $4 \mathrm{M} \mathrm{NaCl}$, and 4 times for $30 \mathrm{~min}$ with distilled water. The resulting DSC is hereafter referred to as GDSC.

With the two other methods, acyl azide and carbodiimide crosslinking, carboxylic acid groups were activated and then linked with amine groups within the collagen. ${ }^{18,22,24,25}$

\section{Aa crosslinking ${ }^{18,25}$}

With this method, the carboxylic acid groups of DSC were first ethylated by treating $1-g$ samples for 6 days during constant mixing in $35 \mathrm{ml}$ ethanol (p.a., E. Merck, Darmstadt, FRG) containing $0.2 \mathrm{M} \mathrm{HCl}$. The samples were then washed with a $0.5 \mathrm{M} \mathrm{NaCl}$ solution, and the ethyl ester groups were converted to hydrazides by immersing the samples in $100 \mathrm{ml}$ of a $5.0 \%(\mathrm{w} / \mathrm{w})$ solution of hydrazine (monohydrate, 99\%; Janssen Chimica, Geel, Belgium) in $0.5 \mathrm{M}$ $\mathrm{NaCl}$ for $24 \mathrm{~h}$ at room temperature. After hydrazide formation, samples were washed with an ice-cold $0.5 \mathrm{M} \mathrm{NaCl}$ solution. Aa formation was performed in $100 \mathrm{ml}$ of a $0.5 \mathrm{M} \mathrm{NaCl}$ solution containing $0.5 \mathrm{M}$ $\mathrm{NaNO}_{2}$ (E. Merck) and $0.3 \mathrm{M} \mathrm{HCl}$ at $0^{\circ} \mathrm{C}$ for $10 \mathrm{~min}$. The next step was washing with $0.02 \mathrm{M} \mathrm{Na}_{2} \mathrm{HPO}_{4}$ buffer ( $\mathrm{pH} 8.9$ ) containing $0.5 \mathrm{M} \mathrm{NaCl}$, followed by crosslinking, by reaction of Aa groups with amine groups in $200 \mathrm{ml}$ buffer ( $\mathrm{pH} \mathrm{8.9)}$ containing $0.5 \mathrm{M}$ $\mathrm{NaCl}$ at room temperature for $48 \mathrm{~h}$. Thereafter, samples were washed 2 times with $4 \mathrm{M} \mathrm{NaCl}$ and 4 times with water before lyophilization. Samples are hereafter referred to as AaDSC.

\section{Carbodiimide crosslinking}

This method was performed with EDC in combination with NHS to suppress side reactions. ${ }^{18,22,25}$ Samples of $1 \mathrm{~g}$ were immersed in $50 \mathrm{ml}$ aqueous solution containing $1.15 \mathrm{~g}$ (6.0 mmol) EDC (MerckSchuchardt) and $0.28 \mathrm{~g}(2.4 \mathrm{mmol})$ NHS (also from Merck-Schuchardt) at room temperature for $2 \mathrm{~h}$. The $\mathrm{pH}$ of the solution was set at 5.5 by the addition of $\mathrm{HCl}$, and was maintained at this value by the addition of $0.1 \mathrm{M} \mathrm{NaOH}$ using a $\mathrm{pH}$ stat apparatus (702 SM Titrino; Metrohm, Herisau, Switzerland). After crosslinking, samples were washed for $2 \mathrm{~h}$ in a $0.1 \mathrm{M} \mathrm{Na}_{2} \mathrm{HPO}_{4}$ solution to hydrolyze remaining NHS-activated carboxylic groups, and were subsequently washed 4 times with distilled water before lyophilization. This material is hereafter referred to as ENDSC. 


\section{Methods}

\section{Characterization}

The degree of crosslinking of the DSC samples was related to the increase in shrinkage temperature (Ts) ${ }^{26}$ Ts of nonsterilized crosslinked DSC samples immersed in water were determined as described previously. ${ }^{20}$ The noncrosslinked NDSC functioned as control. The free amine group content of the samples was determined spectrophotometrically after reaction of the primary amine groups with 2,4,6trinitrobenzene sulfonic acid (TNBS), ${ }^{20}$ and is expressed as the number of amine groups present per 1,000 amino acids.

\section{Ethylene oxide sterilization}

Disks with a diameter of $8 \mathrm{~mm}$ were punched from HDSC, GDSC, AaDSC, and ENDSC. The weight of the disks was approximately $15 \mathrm{mg}$. Disks were then sterilized by ethylene oxide (EO) by exposing the samples to a $100 \%$ EO atmosphere at a relative humidity of $70 \%$ for $5 \mathrm{~h}$ at $55^{\circ} \mathrm{C}$. Subsequently, the samples were aerated with a warm air flow at atmospheric pressures for at least $48 \mathrm{~h}$ to remove residual EO from the DSC matrix. ${ }^{27}$

\section{Methylcellulose cell culture}

The methylcellulose cell culture has been extensively described elsewhere. ${ }^{11-14}$ In short, human fibroblasts (HF) were routinely cultured in RPMI 1640 medium (Gibco Biocult Co., Paisley, U.K.), supplemented with $10 \%$ fetal calf serum (FCS), $2 \mathrm{mmol} / \mathrm{L}$ glutamine (Glut) (Merck), penicillin (Pen), and streptomycin (Strep), both $100 \mathrm{U} / \mathrm{ml}$ (Gibco). Furthermore, a stock solution of $2.25 \%$ methylcellulose (MC), Methocel high viscosity $(3,000-4,000 \mathrm{cps})$ from Fluka (Bio Chemica, Buchs, Switzerland), was prepared with Iscove's modification of Dulbecco's medium (IMDM; ICN Biomedicals Inc., Costa Mesa, CA). After HF were washed twice with PBS, they were harvested from routine culture using $0.25 \%$ trypsin (Gibco). The cells were centrifuged and resuspended in IMDM. $\mathrm{HF}$ /culture gel mixtures were made by gently and thoroughly mixing HF/IMDM $(30 \%)$ with MC (50\%) and FCS $(20 \%)$. Pen, Strep, and Glut had been added to IMDM to obtain the same final concentration in the culture gel as described for RPMI 1640 medium. A final volume of $4.0 \mathrm{ml}$ of culture gel containing $5 \times 10^{4}$ HF was placed into each well of sixwell tissue culture plates (Greiner, Alphen a/d Rijn, The Netherlands). Such cultures were used either as test culture, with two disks of DSC placed in one well, or as control cultures. The cultures were incubated at $37^{\circ} \mathrm{C}$ in air containing $5 \% \mathrm{CO}_{2}$. After $24 \mathrm{~h}$ two disks
( $\pm 30 \mathrm{mg}$ ) of HDSC, GDSC, AaDSC, or ENDSC were placed on top of the $\mathrm{HF} /$ culture gel mixture in each well $(\mathrm{n}=3)$.

After a total culture period of 7 days disks and gel were removed, and cells were trypsinized, resuspended, and counted in a Bürker counting-chamber. The cell growth inhibition, expressed as a percentage of cell proliferation in control culture, was calculated from the mean of counts ( $\pm S D$ ) of three wells.

\section{Implantations}

National Institutes of Health guidelines for the care and use of laboratory animals (NIH 85-23 Rev. 1985) were observed. Male AO rats approximately 3 months of age were ether anaesthetized, and subcutaneous pockets were made to the right and left of two midline incisions on the back. DSC disks were implanted in the pockets at a distance of about $1 \mathrm{~cm}$ from the incisions. Implants with surrounding tissue were carefully dissected from the subcutaneous site at 5 or 10 days and at $3,6,10,15$, and if possible, 20 and 30 weeks.

\section{Microscopy}

Implants were immediately immersion-fixed in $2 \%$ (v/v) GA in $0.1 \mathrm{~mol}$ PBS (pH 7.4). Specimens were cut into small blocks $(2 \times 2 \times 2 \mathrm{~mm})$ after at least $24 \mathrm{~h}$ of fixation at $4^{\circ} \mathrm{C}$. Blocks were postfixed in $1 \%$ $\mathrm{OsO}_{4}, 1.5 \% \mathrm{~K}_{4} \mathrm{Fe}(\mathrm{CN})_{6}$ in $\mathrm{PBS}^{28}$ dehydrated in graded alcohols, and embedded in Epon 812.

Semithin sections $(1 \mu \mathrm{m})$ for light-microscopic evaluations were stained with toluidine blue. Ultrathin sections $(70 \mathrm{~nm})$ were cut and stained with uranyl acetate and lead citrate and examined with a Philips EM 201 transmission electron microscope operated at $40 \mathrm{kV}$.

\section{RESULTS}

\section{Initial properties}

In Table I, the results obtained from the Ts measurements and free amine group content determinations of HDSC, GDSC, AaDSC, and ENDSC, as compared with NDSC, are presented. For NDSC samples, a Ts of $56^{\circ} \mathrm{C}$ was found. Crosslinked samples had increased Ts values, indicating that crosslinking had occurred. ${ }^{18-20,22,24,25}$ Of the crosslinked samples, HDSC had the lowest Ts of $74^{\circ} \mathrm{C}$, whereas the highest Ts was observed for ENDSC $\left(86^{\circ} \mathrm{C}\right)$. The observed free amine group content of 34 per 1,000 amino acid residues for NDSC is in good agreement with values reported in the literature. ${ }^{29}$ HDSC, AaDSC, and ENDSC had similar free amine group content of 17 
TABLE I

Shrinkage Temperature and Free Amine Group Content of HDSC, GDSC, AaDSC, and ENDSC Compared with NDSC

\begin{tabular}{lcc}
\hline Sample & $\begin{array}{c}\text { Shrinkage } \\
\text { Temperature }\left({ }^{\circ} \mathrm{C}\right)\end{array}$ & $\begin{array}{c}\text { Amine Group } \\
\text { Content }(\mathrm{n} / 1,000)\end{array}$ \\
\hline NDSC & $56.0 \pm 0.3$ & $33.7 \pm 0.3$ \\
HDSC & $73.8 \pm 0.3$ & $16.9 \pm 0.4$ \\
GDSC & $77.7 \pm 0.3$ & $9.9 \pm 0.2$ \\
AaDSC & $82.4 \pm 0.4$ & $16.7 \pm 0.3$ \\
ENDSC & $86.6 \pm 0.4$ & $16.0 \pm 0.5$ \\
\hline
\end{tabular}

per 1,000 amino acid residues. GDSC samples had the lowest free amine group content of 10 per 1,000 amino acid residues.

\section{Methylcellulose cell culture}

With MC cell culture, the optimized HMDICcrosslinked HDSC samples were found to induce $13.4 \pm 10.1 \%$ of cell growth inhibition, whereas cells had normal morphologies. The cytotoxic effects of GDSC were considerably decreased to $16.0 \pm 4.7 \%$ cell growth inhibition, with only a small cell-free zone with lipid degeneration in cells at the edge. Both the Aa-crosslinked AaDSC and the EDC/NHScrosslinked ENDSC, with respective cell growth inhibitions of $-2.2 \pm 4.9 \%$ and $-4.5 \pm 3.4 \%$ and normal morphologies, were found to be noncytotoxic.

\section{Subcutaneous implantations}

Before implantation, all DSC samples had a fibrous structure macroscopically. ENDSC was qualita- tively less wettable compared with the other samples. Microscopically, the crosslinked DSC samples consisted of a matrix of collagen bundles. Elastin-like substances of former blood vessels sometimes lined collagen bundles. In contrast to previous DSC batches, which sometimes contained aluminum silicate ( $\mathrm{Al} / \mathrm{Si}$ ) crystals, ${ }^{15-17}$ these crystals were rarely observed with the materials used in this study.

After implantation, harvesting of HDSC and GDSC was difficult from 10 weeks onward, because the disks had become very small. The remnants of these implants had completely disappeared after 15 weeks. Disks of the original size could easily be retrieved after 30 weeks, when AaDSC or ENDSC had been implanted.

\section{HDSC}

At day 5, compared with commercial $\mathrm{HDSC}^{15,16}$ only some neutrophils and macrophages had infiltrated the HDSC implants (Table II). The infiltration had not proceeded through the entire implant. The neutrophils and macrophages hardly showed degeneration and had normal morphologies. Only at the outer edges was observed a small rim of ingrowth containing foreign body multinucleated giant cells and fibroblasts.

After 10 days, cell ingrowth had slowly but clearly proceeded, as judged by the somewhat larger rim with macrophages, giant cells, and fibroblasts, as well as from the presence of capillaries and some newly formed rat collagen all throughout the implant (Fig. 1a). A few basophil-like cells were present, but neutrophils were no longer observed. Giant cells had surrounded and also included parts of HDSC, and

TABLE II

Material Tissue Interactions

\begin{tabular}{|c|c|c|c|c|}
\hline & HDSC & GDSC & AaDSC & ENDSC \\
\hline Neutrophils & Some & Increased numbers, deviant & Some & Some \\
\hline Macrophages & Some & Many & $\begin{array}{l}\text { Many, lipid degen- } \\
\text { eration }\end{array}$ & Some \\
\hline Giant cells & $\begin{array}{c}\text { Some at day } 10 ; \\
\text { later, many }\end{array}$ & Few & $\begin{array}{l}\text { Many from day 10, } \\
\text { degen. mito's }\end{array}$ & $\begin{array}{c}\text { Some at day 10; } \\
\text { later, many }\end{array}$ \\
\hline $\begin{array}{l}\text { Fibroblasts } \\
\text { collagen }\end{array}$ & $\begin{array}{l}\text { New collagen: } \\
\text { day } 10 \\
\text { to week } 15\end{array}$ & $\begin{array}{l}\text { Hardly any day } 10 \text { to } \\
\text { week } 15\end{array}$ & $\begin{array}{l}\text { New collagen } \\
\text { day } 10 \text { to } \\
\text { week } 30\end{array}$ & $\begin{array}{l}\text { New collagen } \\
\text { day } 10 \text { to } \\
\text { week } 30\end{array}$ \\
\hline Basophils & $\begin{array}{l}\text { Mainly from } \\
\text { week } 3 \\
\text { onward }\end{array}$ & Few & $\begin{array}{l}\text { Many, from week } 3 \\
\text { onward }\end{array}$ & $\begin{array}{l}\text { Mainly from } \\
\text { week } 6 \\
\text { onward }\end{array}$ \\
\hline Lymphocytes & Few & Few & $\begin{array}{l}\text { Some, from week } 6 \\
\text { onward }\end{array}$ & $\begin{array}{l}\text { Some, from } \\
\text { week } 6 \\
\text { onward }\end{array}$ \\
\hline Calcification & None & $\begin{array}{l}\text { Slight, day 10; } \\
\text { later, high }\end{array}$ & $\begin{array}{l}\text { Slight, only at } \\
\text { week } 3\end{array}$ & $\begin{array}{l}\text { Moderate, only } \\
\text { at week } 6\end{array}$ \\
\hline Degradation & week 15 & week 15 & Not yet at week 30 & $\begin{array}{l}\text { Not yet at } \\
\text { week } 30\end{array}$ \\
\hline
\end{tabular}




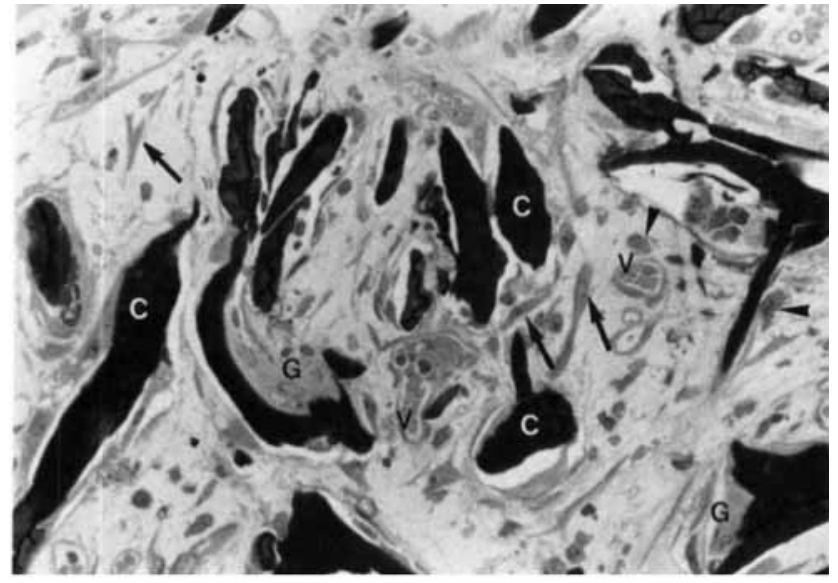

(a)

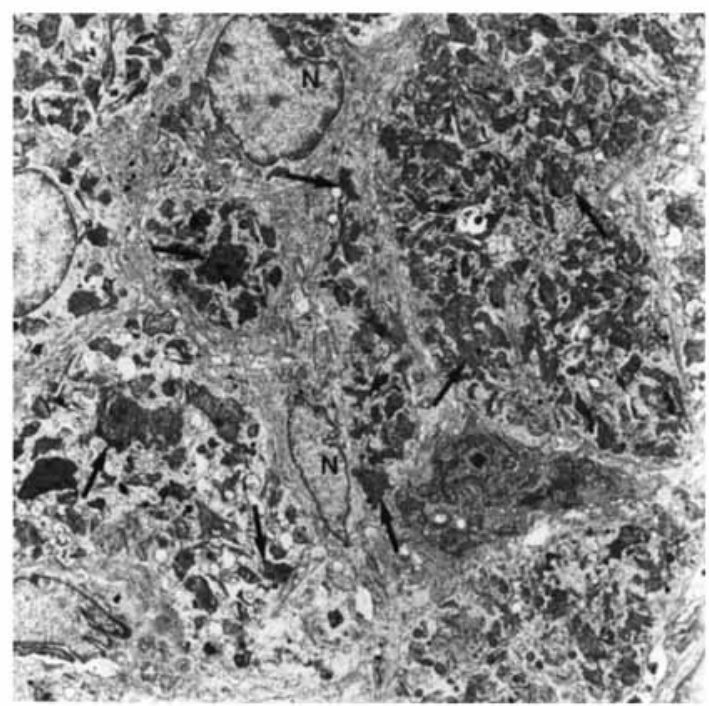

(b)

Figure 1. a: $(\times 1,000$.) HDSC at day 10. LM micrograph showing the outer rim with collagen bundles $(C)$, blood vessels (V), giant cells (G), macrophages (arrowheads) and fibroblasts (arrows). At this time, HDSC was not completely infiltrated. b: $(\times 4,685)$ HDSC at week 10 . TEM micrograph showing smaller giant cells with numerous phagosomes (arrows) possibly containing denatured collagenous material. $N$ : nucleus.

often showed degenerated mitochondria. Fibroblasts with well-developed rough endoplasmic reticulum were actively forming new collagen, which could be recognized by the presence of fibers with small diameters.

At week 3, HDSC was completely infiltrated and contained many macrophages and giant cells with incorporated parts of HDSC and degenerated mitochondria. Furthermore, a large amount of newly formed rat collagen, many active fibroblasts, capillaries, and larger blood vessels were present in the implant. The number of basophil-like cells had somewhat increased.
After 6 and 10 weeks, the size of the implants had clearly decreased. At both time intervals, mainly smaller-sized giant cells with many phagosomes were observed (Fig. 1b). At LM level, the only recognizable HDSC parts were remnants of former blood vessels with elastin-like substances. Probably, collagen from the original implant was no longer present. The bundles of collagen fibrils observed, present in wavelike patterns, seemed all of rat origin. Also, many basophil-like cells were present. Especially around small blood vessels, several lymphocytes were observed. The surrounding fibrous capsule contained several mast cells around blood vessels and only a few active fibroblasts.

At 15 weeks, the remnants of the implants consisted mainly of the previously mentioned smaller-sized giant cells with phagosomes. At a later time, remnants of HDSC could no longer be retrieved.

Calcification of HDSC was never observed.

\section{GDSC}

Compared with HDSC, GDSC showed an increased cell infiltration and cell death of both neutrophils and macrophages at day 5 (Table II; Fig. 2a). Furthermore, a thicker and more active fibrous capsule was observed. The neutrophils sometimes showed disintegration of the cytoplasm (Fig. 2b). Overall, this was only a slight reaction, compared with the reaction to commercially available GDSC. ${ }^{16}$

At day 10 cell morphologies were generally not optimal. Intracellular and extracellular lipid and poorly adhering macrophages were observed. A clear rim containing giant cells and fibroblasts, as observed with HDSC was not present. Collagen bundles started to calcify, i.e., small deposits of electron-dense needlelike crystals were observed at the TEM level.

At 3 weeks, calcification had proceeded, showing larger deposits as observed at both the LM and TEM levels (Fig. 3a and b). The cellular ingrowth of all cell types including basophils was less than with HDSC at this time. In between collagen fibrils and cells, unoccupied spaces were observed, and cell pseudopodia did not completely adhere to and surround collagen fibrils (Fig. 3b).

After 6 and 10 weeks, completely calcified collagen structures were observed, indicating that calcification had proceeded further. At the LM level, this gave the impression of empty-looking implants, because the deposits were poorly stained. Only the outer rim showed complete occupation with cells, and possibly new rat collagen. Within the implant, newly formed rat collagen was hardly observed, although capillaries and some infiltration of all cell types were present throughout the implant. The capsule was still thick and contained large amounts of newly formed rat 


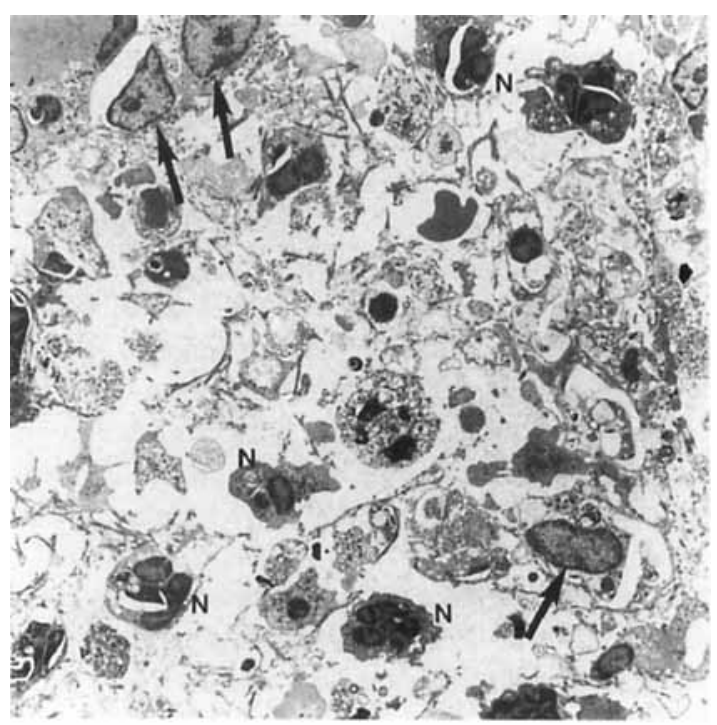

(a)

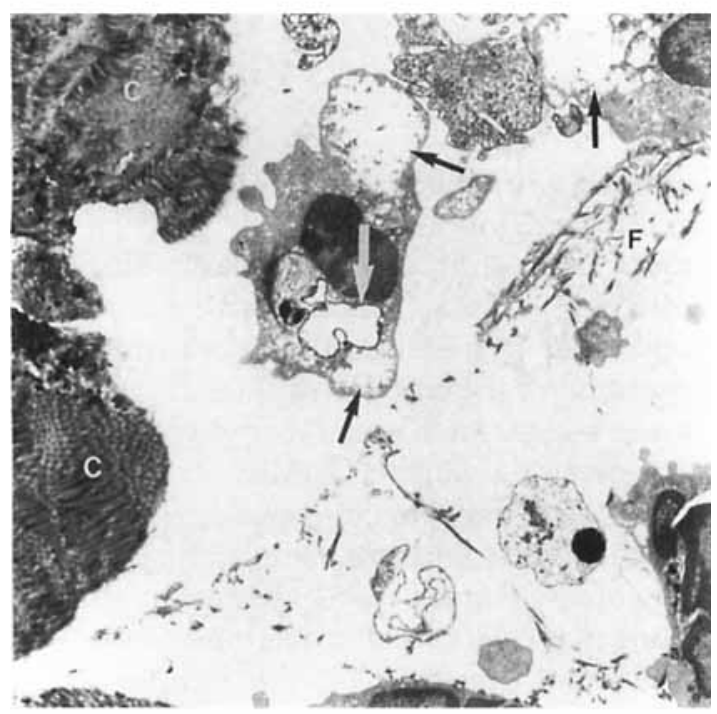

(b)

Figure 2. GDSC at day 5. a: $(\times 3,226$.$) TEM micrograph$ of infiltrating cells. Judging by the nuclei, neutrophils (N) and macrophages (arrows) are involved, whereas many degenerating cells are also observed. b: $(\times 7,142$.) TEM micrograph of neutrophils with deviant morphology between collagen bundles. F: fibrin network; $C$ : collagen. The neutrophils show a disintegration of the glycogen in the cytoplasm (black arrows), swollen mitochondria, and lipid formations (white arrows).

collagen, but active fibroblasts were only sporadically found.

Between 10 and 15 weeks, calcium-containing deposits obviously started to disappear, possibly via an extracellular pathway, because at week 15 , only a small remnant without collagen of sheep origin was found (Fig. 4a and b). At the TEM level, these structures no longer showed a specific morphology, although a light electron-dense substance

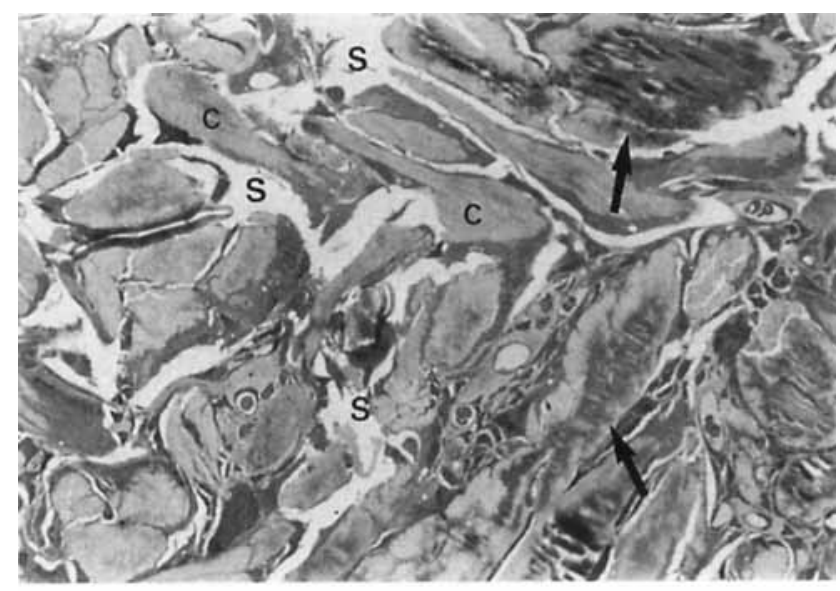

(a)

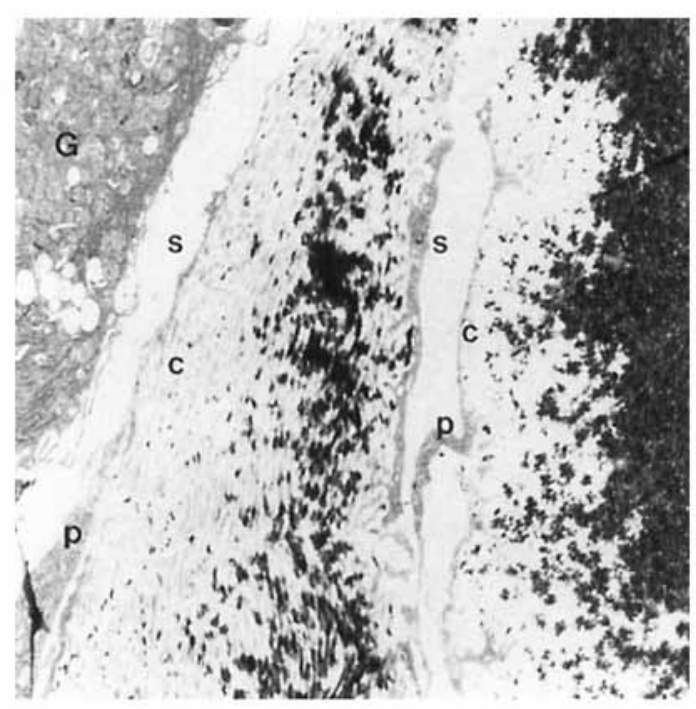

(b)

Figure 3. GDSC at week 3 . a: $(\times 1,000$.) LM micrograph of cellular infiltration between collagen bundles (C). Unoccupied spaces (S) as well as irregularities in the color of collagen bundles (arrows) are observed. b: $(\times 7,142$.) TEM micrograph of part of a giant cell $(G)$, unoccupied spaces (S), collagen bundles (C), and pseudopods $(P)$ of other cells. The black spots on the collagen represent calcification. The spaces indicate that cells do not adhere closely to the collagen.

was still present (Fig. 4b). Vascularization was observed, whereas only a few giant cells and almost no new collagen were seen. The latter was easily recognized from its fine, immature structure. Several lymphocytes were present. At a later time, remnants of GDSC were no longer retrieved.

\section{AaDSC}

Few neutrophils, but many macrophages were found to infiltrate AaDSC implants at days 5 and 10 (Table II). The macrophages showed a high incidence of lipid droplet formation and accumulation 
(Fig. $5 a$ and b). At day 10 , the cellular reaction had proceeded and the implants had been almost completely infiltrated with macrophages, giant cells, and fibroblasts. Many lipid droplets were observed in giant cells, which were especially prominent at 3 weeks (Fig. 6a). Furthermore, at this time, many basophil-like cells (Fig. 6b) were observed in and around the implant. New collagen was actively formed. Only at this time was a slight calcification observed in collagen structures, probably from sheep.

At 6 and 10 weeks, the previously described processes continued. In addition, some lymphocytes were observed, mainly near blood vessels.

After 15 weeks, when remnants of HDSC and GDSC could hardly be retrieved, bundles of collagen fibrils, probably from both sheep and rat, were present in the AaDSC samples. Both the finer structure, as well as the included membranous structures from degenerated cells, ${ }^{13}$ sometimes clearly indicated the rat origin of certain collagen structures. Active fibroblasts, giant cells, basophil-like cells, and blood vessels were observed in the implant.

At 20 weeks, it was easier to discriminate between the two origins of collagen, because fewer giant cells surrounded the collagen, indicating that it was no longer of foreign origin. At 30 weeks, a disk of almost the original size was explanted, although it probably consisted entirely of rat collagen with just a few remnants of giant cells associated with collagen from sheep (see below). Furthermore, between the collagen fibrils, several lymphocytes were present.

\section{ENDSC}

The reaction at 5 and 10 days to ENDSC (Table II) was similar to that observed with HDSC, i.e., a somewhat increased neutrophil and macrophage infiltration, but no deviant cell morphologies were observed. The ingrowth of giant cells and fibroblasts occurred slowly, in a similar way as with HDSC, with a completely infiltrated disk from week 3 onward. Giant cells thereby actively surrounded and included collagen structures. They often showed degenerated mitochondria. New collagen was actively formed from day 10 onward, as observed from fibroblasts containing high amounts of well-developed rough endoplasmic reticulum. Basophils, although not in high numbers, were observed from week 6 onward. Only at this time was moderate calcification of collagen bundles found. The implant contained basophil-like cells (Fig. 7a), although they were fewer than with AaDSC. From this time onward, several lymphocytes were observed near blood vessels.

At 15 weeks, giant cells, fibroblasts, and capillaries were still present in the implant, and new rat collagen was actively formed. At 20 (Fig. $7 \mathrm{~b}$ ) and 30 weeks this process had continued, and, similar to AaDSC, with probably only rat collagen present in a disk of about the original size at 30 weeks. Blood vessels and several lymphocytes were observed between the collagen structures (Fig. 7b).

\section{DISCUSSION}

Collagen-based biomaterials may be used as scaffolds for the regeneration of missing or injured parts of the body. Especially in the repair of tissues, which consist predominantly of collagen, i.e., tendon ${ }^{3}$ or ligaments, ${ }^{4,5}$ this may be a successful approach toward healing. Controlling the rate of degradation by crosslinking such implants not only determines the lifetime of the material after application, but may also determine the rate of tissue regeneration. Previously, we optimized the HMDIC- and GAcrosslinking of DSC resulting in modified HDSC ${ }^{18,19}$ or GDSC. ${ }^{18,20}$ Furthermore, the Aa- and the ENmethods have been used in the crosslinking of DSC. ${ }^{18,22,25}$ In the present study, the biocompatibility and tissue-regenerating capacity of these crosslinked DSC samples were studied.

\section{Biocompatibility}

Using the MC cell culture with human skin fibroblasts, ${ }^{11}$ both AaDSC and ENDSC were found to be noncytotoxic. HDSC and GDSC showed low cell growth inhibitions of 13 and $16 \%$, respectively, with only GDSC showing a small cell-free zone and lipid degeneration at the edge.

After subcutaneous implantation, the infiltration of neutrophils and macrophages in ENDSC was seldom different from the infiltration occurring during normal wound healing after surgical injury. Moreover, the cells present had no deviance in morphology. These results confirm the in vitro results that showed that ENDSC is not cytotoxic.

Although HDSC samples showed low cytotoxity in vitro, this was not verified in vivo. No specific cytotoxic effects were detected, and results were similar to those of ENDSC.

In contrast, GDSC samples, which also showed low cytotoxicity in vitro, resulted in a slight cytotoxic effect after implantation. Although mild compared with commercially available GDSC, an increased cell infiltration and degeneration and a deviant neutrophil morphology were found. The in vitro cytotoxicity of the GDSC samples could be related to the release of unreacted GA or GA-related compounds from the samples, ${ }^{14}$ which may also explain the in vivo cytotoxicity of these samples. Furthermore, polypeptide fragments containing cytotoxic groups may be released from these materials because of intracellular 


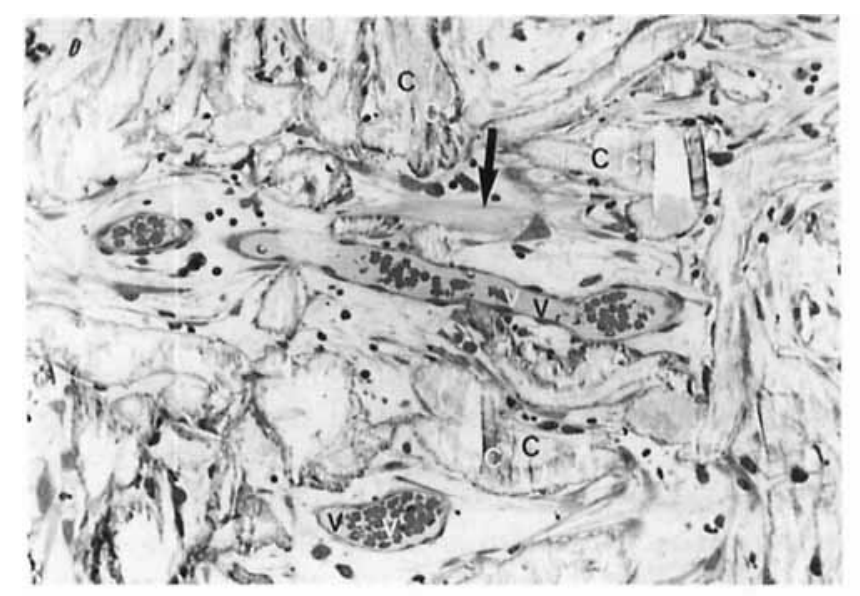

(a)

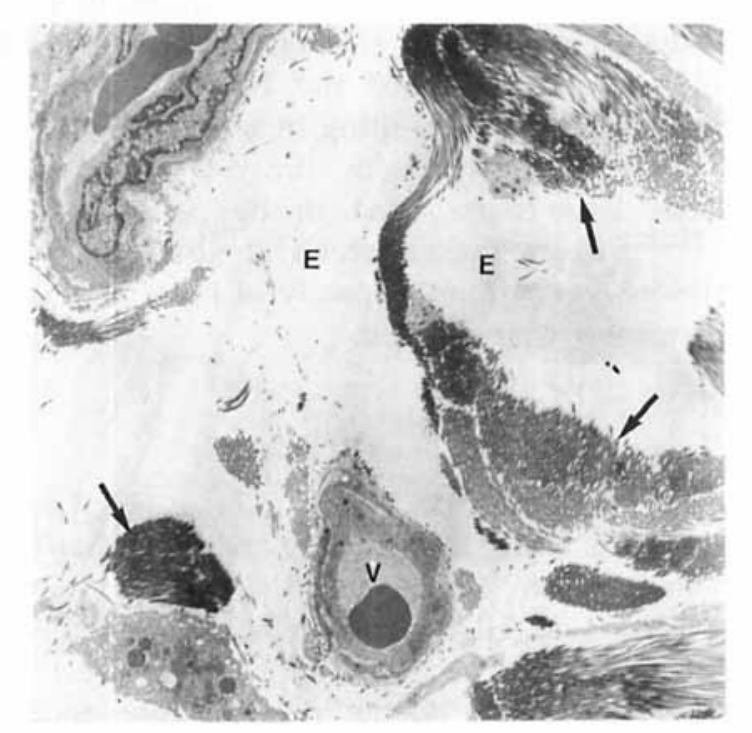

(b)

Figure 4. GDSC at week 15. a: $(\times 640$.) LM micrograph showing the empty-looking remnants of the implant. Collagen bundles (C) have been completely calcified, whereas part of the calcific deposits may even have disappeared. In between, mostly unoccupied spaces (S) and only few cells, of which the blood vessels (V) with erythrocytes are the most obvious, and collagen bundles of rat origin (arrow), are observed. b: $(\times 4,685$.) TEM micrograph with light electron-dense spaces (E) of former calcified collagen bundles, blood vessels (V), and small bundles of rat collagen (arrows).

or extracellular enzymatic degradation of the GDSC samples. ${ }^{14}$

With the AaDSC samples, in vitro and in vivo results appeared to disagree. Although these samples were noncytotoxic in vitro, the increased infiltration of macrophages and giant cells, both with lipid accumulation, may be seen as a cytotoxic effect. During the Aa crosslinking, the carboxylic acid groups of DSC were permanently modified into ethyl ester groups, hydrazide groups, or Aa groups. ${ }^{25}$ These groups could still be present in AaDSC, which may explain the

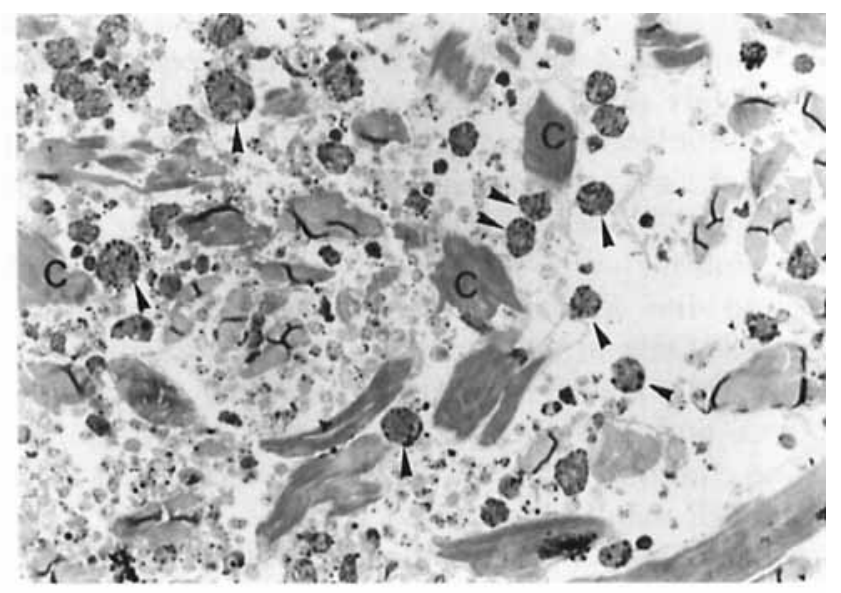

(a)

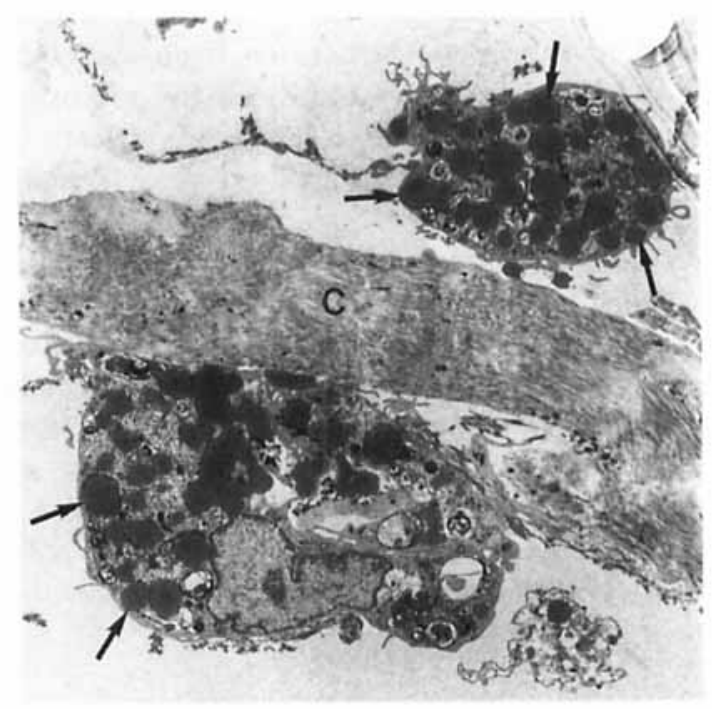

(b)

Figure 5. AaDSC at day 5. a: (×640.) LM micrograph of cell infiltration between collagen bundles (C). Apart from some individual cells, which are macrophages (arrows), identification of the partially degenerating cells is difficult. b: $(\times 4,685$.) TEM micrograph with macrophages and a collagen bundle (C). The macrophages contain many lipid droplets (arrows).

cytotoxic reaction. That this cytotoxic effect was not detected during in vitro testing of the AaDSC samples may be the result of the use of fibroblasts in MC cell culture. Also, in vivo fibroblasts seemed not to react in a deviant way to AaDSC; the in vivo cytotoxic reaction seemed to be specific for macrophages and giant cells. Basophil-like cells were previously described for the commercially available DSC samples, ${ }^{15-17}$ and their presence was suggested to be clearly related with the occurrence of $\mathrm{Al} / \mathrm{Si}$ crystals found in these materials. ${ }^{16}$ However, basophil-like cells were observed in all materials and especially in AaDSC, whereas $\mathrm{Al} / \mathrm{Si}$ crystals were rarely found in these materials. Therefore, we now think that the reaction of basophil-like cells is related not only to the presence of $\mathrm{Al} / \mathrm{Si}$ - 


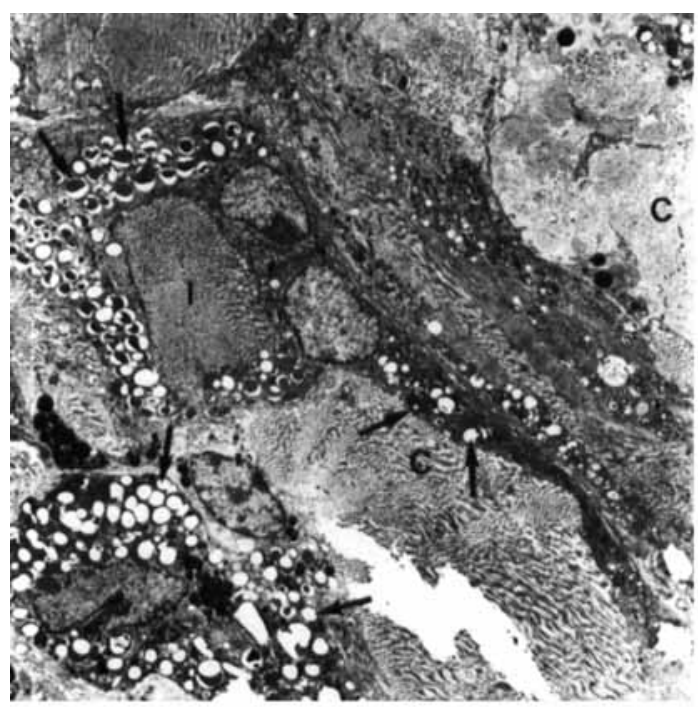

(a)

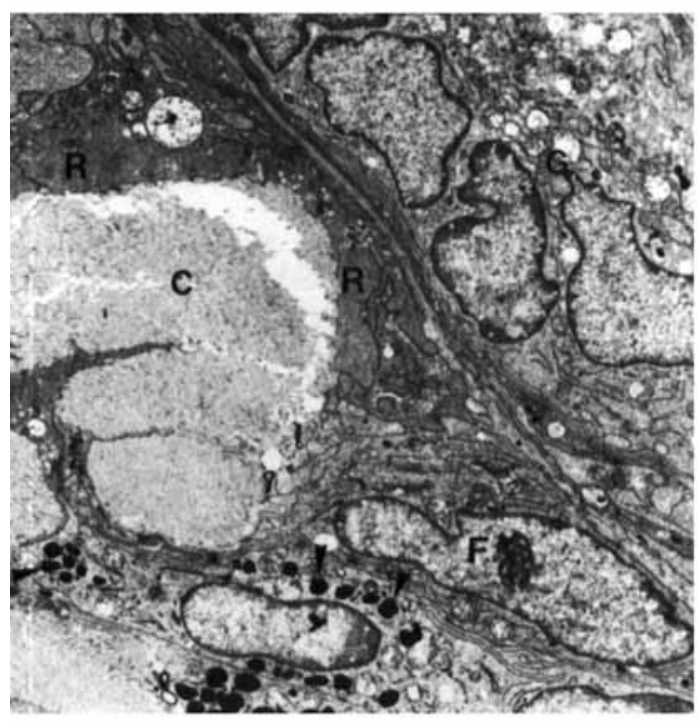

(b)

Figure 6. a: $(\times 3,226$.$) AaDSC at week 3. TEM micro-$ graph showing complete occupation with cells between collagen bundles $(\mathrm{C})$. The bundles have been surrounded or included (I) by giant cells. The giant cells contain numerous lipid droplets (arrows). Lipid was partially removed during processing for TEM. $b:(\times 7,142$. $)$ AaDSC at week 6 . TEM micrograph showing a sheep collagen bundle $(\mathrm{C})$, an active fibroblast $(\mathrm{F})$, and newly formed rat collagen (R), a giant cell with four nuclei, and a basophil-like cell containing basophil-like granules (arrows).

crystals, as suggested before ${ }^{16}$ but also to the presence of foreign collagen itself. The presence of basophillike cells, just like normal basophilic granulocytes and mast cells, ${ }^{30-32}$ may represent a slightly allergic type of reaction. The same conclusion is drawn for the presence of several lymphocytes, from week 6 onward, in remnants of AaDSC and ENDSC. As to

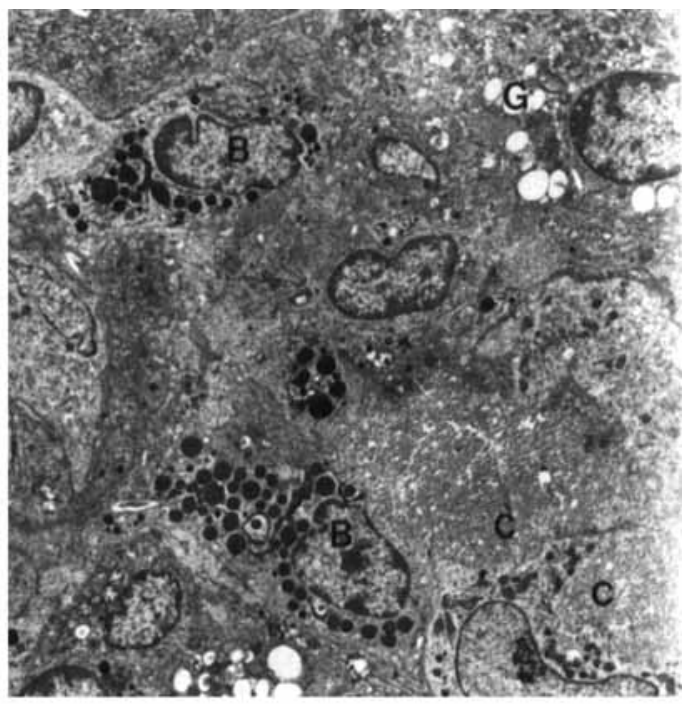

(a)

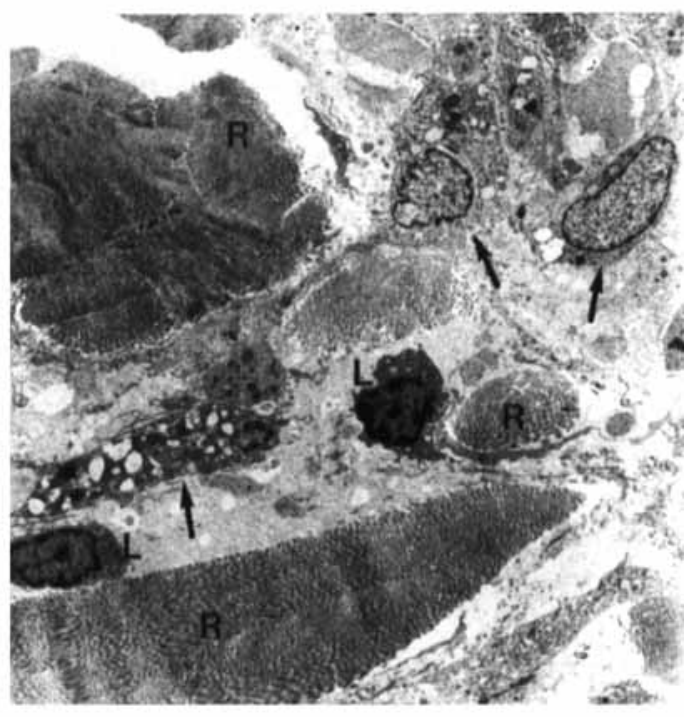

(b)

Figure 7. a: $(\times 4,685$. $)$ ENDSC at week 6. TEM micrograph showing a giant cell $(\mathrm{G})$ and several basophil-like cells (B). At this stage, it is difficult to discriminate between collagen $(C)$ of sheep and rat origin. $b:(\times 3,226$.) ENDSC at week 20 . TEM micrograph showing probably only rat collagen (R), which is no longer intensely surrounded by giant cells. Some degenerating giant cells (arrows) are still present, as well as two lymphocytes (L).

the minimal presence of $\mathrm{Al} / \mathrm{Si}$ crystals, it may be that it previously concerned certain batches of DSC. ${ }^{15-17}$

\section{Tissue-regenerating capacity}

$N$-hydroxysuccinimide and AaDSC implants clearly functioned as temporary scaffolds, resulting, at 30 weeks, in collagen matrices of probably only rat collagen and without giant cells. However immunohistochemistry is needed strictly to discriminate 
between collagen of either sheep or rat origin. The previously described macrophage reaction observed with AaDSC makes ENDSC the more favorable material as a temporary scaffold for the production of an entirely new and completely biocompatible fibrous tissue.

Similar to ENDSC and AaDSC, HDSC induced the formation of new collagen. However, at 10 and 15 weeks with HDSC, little newly formed collagen was present, at least in the way of a collagen matrix, such as was observed with AaDSC and ENDSC at 20 and 30 weeks. The remnants of HDSC could not be retrieved at later times than 15 weeks after implantation. The most prominent cell type present at 10 and 15 weeks was the smaller-sized giant cell with phagosomes. The phagosomes, not found with the other crosslinked DSC samples, probably contained denatured collagenous parts of HDSC.

Of the samples studied, only GDSC did not function as a temporary scaffold for the regeneration of tissue, because hardly any new formation of collagen occurred. Obviously, fibroblasts did not experience the collagen bundles of GDSC as substrates to which to adhere and migrate, and on which to proliferate and produce collagen. Also, giant cells obviously did not experience GDSC as foreign or in some other way found it unattractive for adhesion and surrounding. Both phenomena might be explained by the high incidence of calcification of the GDSC implants. The occurrence of calcification of GA-crosslinked collagens has also been reported by other groups..$^{32-35}$ Possible mechanisms of DSC calcification will be discussed in a forthcoming article. ${ }^{36}$ Because remnants of GDSC were not found at later times than 15 weeks, and calcified collagen structures had not been removed by phagocytosing giant cells, extracellular dissolution seems to be the degradation pathway.

\section{CONCLUSIONS}

Of the four crosslinked DSC types, ENDSC seems the most promising material for applicative studies. Both in vitro and in vivo, it was shown to be biocompatible, and it induced regeneration of a new collagen matrix during a slow degradation rate. ENDSC may therefore be suitable for applications such as tendon or ligament replacement. So far, it has been tested in a follow-up study on repair material for the abdominal wall. ${ }^{37}$ Preliminary results confirm the slower degradation compared with commercially available HDSC. A much longer persistence of newly formed fibrous tissue was observed. Moreover, indications of ENDSC functioning as guidance for muscle overgrowth were found. At present, we are searching for some cell biologic stimulation to promote muscle growth, and thus formation of an entirely new abdominal wall.
Of the three other crosslinked DSC types, HDSC may be of secondary interest. It was also found to be biocompatible, but it degraded much faster than ENDSC. However, it showed no sign of calcification, which may make HMDIC crosslinking suitable for the production of heart valve bioprostheses.

Finally, our data may be of use for a better understanding and further improvement of the function of collagen-based biomaterials in general.

The authors acknowledge Mr. E. H. Blaauw for the embedding of the specimens and Mr. D. Huizinga and Mr. P. van der Sijde for the photography.

\section{References}

1. A.C. van der Wal, N.J.M. Out, Van den Hooff, and P. J. Klopper, "Reconstruction of the abdominal wall with processed dermal sheep collagen-an experimental study in dogs," Implant Materials in Biofunction, C. De Putter, G. L. De Lange, K. De Groot, and A.J.C. Lee, eds., Elsevier Science Publishers BV, Amsterdam, 1988, pp. 61-66.

2. J.S. van der Laan, P.B. van Wachem, J.M. Schakenraad, and P. Nieuwenhuis, "Dermal sheep collagen for the repair of abdominal wall defects," Int. J. Artif. Organs, 14, 661-666 (1991).

3. A. J. Wasserman, Y. Pedro Kato, D. Christiansen, M.G. Dunn, and F.H. Silver, "Achilles tendon replacement by a collagen fiber prosthesis: Morphological evaluation of neotendon formation," Scanning Microsc., 3, 1183-1200 (1989).

4. P.J. Steinberg, "The use of high-grade processed dermal sheep collagen in cruciate ligament substitution," Eur. Surg. Res., 19 (suppl. 1), 30 (1987).

5. J. L. Berry, W.S. Berg, T.M. Stahursky, J. M. Moran, E.M. Morgan, and A.S. Greenwald, "Evaluation of Dacron-covered and plain bovine xenografts as replacements for the anterior cruciate ligament," Clin. Orthop. Rel. Res., 236, 270-278 (1988).

6. J.J.G. Bannenberg, K. Breuker, A. van der Wal, J. Feijen and P.J. Klopper, "Processed dermal sheep collagen as a small diameter vascular graft," Eur. Surg. Res., 19, 69-75 (1987).

7. J. A. Werkmeister, G. A. Edwards, V. Glattauer, T. A. Tebb, G. Roberts, and J. A. M. Ramshaw, "Structural stability of long-term implants of a collagen-based vascular prosthesis," I. Long-term Effects Medical Implants, 1, 107-119 (1991).

8. K. Anselme, C. Baques, G. Charriere, D.J. Hartmann, D. Herbage, and R. Garrone, "Tissue reaction to subcutaneous implantation of a collagen sponge. A histological, ultrastructural, and immunological study," J. Biomed. Mater. Res., 24, 689-703 (1990).

9. S.D. Gorham, T. P. Hyland, D. A. French, and M.J. Willins, "Cellular invasion and breakdown of three different collagen films in the lumbar muscle of the rat," Biomaterials, 11, 113-118 (1990).

10. S. Srivastava, S.D. Gorham, and J.M. Courtney, "In vivo evaluation and comparison of collagen, acetylated collagen and collagen/glycosaminoglycan composite films and sponges as candidate biomaterials," Biomaterials, 11, 155-161 (1990).

11. M.J.A. van Luyn, P.B. van Wachem, L. Olde Damink, H. ten Hoopen, J. Feijen, and P. Nieuwenhuis, "Methylcellulose culture as a new cytotoxicity 
test system for biomaterials," J. Mater. Sci. Mater. Med., 2, 142-148 (1991).

12. M.J. A. van Luyn, P. B. van Wachem, L. Olde Damink, J. Feijen, and P. Nieuwenhuis, "Enzymepretreatment removes cytotoxic effects of dermal sheep collagen," in Tissue Inducing Biomaterials, Linda G. Cima and Eyal Ron, eds., 1992, pp. 167-174.

13. M.J.A. van Luyn, P.B. van Wachem, L. Olde Damink, J. Feijen, and P. Nieuwenhuis, "Relations between in vitro cytotoxicity and crosslinking of collagen," J. Biomed. Mater. Res., 26, 1091-1110 (1992).

14. M. J. A. van Luyn, P.B. van Wachem, L. Olde Damink, J. Feijen, and P. Nieuwenhuis, "Secondary cytotoxicity of (crosslinked) dermal sheep collagen during repeated exposure to human fibroblasts," Biomaterials, 13, 1017-1024 (1992).

15. P. B. van Wachem, M. J. A. van Luyn, H. K. Koerten, L. Olde Damink, $H$. ten Hoopen, J. Feijen, and P. Nieuwenhuis, "In vivo degradation of processed dermal sheep collagen evaluated with transmission electron microscopy," Biomaterials, 12, 215-223 (1991).

16. P. B. van Wachem, M. J. A. van Luyn, H. K. Koerten, L. Olde Damink, H. ten Hoopen, J. Feijen, and P. Nieuwenhuis, "Tissue interactions with dermal sheep collagen implants: A transmission electron microscopical evaluation," Cell Materials, 1, 251-263 (1991).

17. P.B. van Wachem, M. J. A. van Luyn, L. H. H. Olde Damink, P. J. Dijkstra, J. Feijen, and P. Nieuwenhuis, "In vivo interactions with (tissue culture pretreated) dermal sheep collagen," in Tissue Inducing Biomaterials, Linda G. Cima and Eyal Ron, eds., 1992, pp. 117-124.

18. L.H.H. Olde Damink, P.J. Dijkstra, M.J.A. van Luyn, P. B. van Wachem, P. Nieuwenhuis, and J. Feijen, "In vitro comparison of collagen crosslinking methods," abstract, Fourth World Biomaterials Congress, Berlin, FRG, April 24-28, 1992, p. 45.

19. L.H.H. Olde Damink, P.J. Dijkstra, M. J. A. van Luyn, P. B. van Wachem, P. Nieuwenhuis, and J. Feijen, "Crosslinking of dermal sheep collagen using hexamethylene diisocyanate," in preparation

20. L.H.H. Olde Damink, P.J. Dijkstra, M.J. A. van Luyn, P.B. van Wachem, P. Nieuwenhuis, and J. Feijen, "Glutaraldehyde as a crosslinking agent for collagen-based biomaterials," in preparation.

21. H. Petite, I. Rault, I. Huc, P. Menasche, and D. Herbage, "Use of the acryl azide method for crosslinking collagen-rich tissues such as pericardium," J. Biomed. Mater. Res., 24, 179-187 (1990).

22. L. H. H. Old Damink, P. J. Dijkstra, M. J. A. van Luyn, P. B. van Wachem, P. Nieuwenhuis, and J. Feijen, "Crosslinking of dermal sheep collagen using a water soluble carbodiimide," in preparation.

23. T. M. van Gulik and P.J. Klopper, "The processing of sheepskin for use as a dermal collagen graft - an experimental study," Neth. J. Surg., 39, 90-94 (1987).

24. L. H. H. Olde Damink, H. ten Hoopen, P.J. Dijkstra, M. J. A. van Luyn, P. B. van Wachem, P. Nieuwenhuis, and J. Feijen, "Changes in the mechanical properties of dermal sheep collagen during in vitro degradation," in preparation.

25. L. H.H. Olde Damink, P. J. Dijkstra, M. J. A. van Luyn, P.B. van Wachem, P. Nieuwenhuis, and J. Feijen, "In vitro degradation of dermal sheep collagen crosslinked using carboxylic acid activating methods," in preparation.

26. P.J. Flory and R.R. Garrett, "Phase transitions in collagen and gelatin systems," J. Am. Chem. Soc., 80, $4836-4845$ (1958).

27. L.H.H. Olde Damink, P.J. Dijkstra, M. J. A. van Luyn, P.B. van Wachem, P. Nieuwenhuis, and J. Feijen, "Influence of ethylene oxide gas treatment on the in vitro degradation of dermal sheep collagen," in preparation.

28. E. H. Blaauw, J. A. Oosterbaan, and J.M. Schakenraad, "Improved Epon embedding for biomaterials," Biomaterials, 10, 356-358 (1989).

29. P. Nedkov, R. Glanvile, I. Goshev, and K. Kühn, "Isolierung und teilweise Charakterisierung von Schafshautkollagen, in Lösung gebracht mit Hilfe von Subtilisin DY," Leder, 34, 54-58 (1983).

30. M. Bessis and R. I. Weed, Living Blood Cells and Their Ultrastructure, Springer-Verlag, New York, 1973.

31. S.J. Galli, "Biology of disease: New insights into 'the riddle of mast cells': Microenvironmental regulation of mast cell development and phenotypic heterogeneity," Lab. Invest., 62, 5-33 (1990).

32. L. Weiss, Cell and Tissue Biology and Textbook of Histology, 6th ed., Urbun and Schwarzenberg, Baltimore, 1988, pp. 157-209.

33. R.J. Levy, F.J. Schoen, R. S. Sherman, J. Nichols, M. A. Hawley, and S. A. Lund, "Calcification of subcutaneously implanted type I collagen sponges: Effects of formaldehyde and glutaraldehyde pretreatments," Am. J. Pathol., 122, 71 (1986).

34. F.J. Schoen, H. Harasaki, K. M. Kim, H.C. Anderson, and R.J. Levy, "Biomaterial-associated calcification: Pathology, mechanisms, and strategies for prevention," J. Biomed. Mater. Res. Appl. Biomater., 22, 11-36 (1988).

35. D.P. Speer, M. Chavpil, C.D. Eskelson, and J. Ulreich, "Biological effects of residual glutaraldehyde in glutaraldehyde tanned collagen biomaterials," J. Biomed. Mat. Res., 14, $753-764$ (1980).

36. M. J. A. van Luyn, P. B. van Wachem, L. H. H. Olde Damink, P. J. Dijkstra, J. Feijen, and P. Nieuwenhuis, "Calcification of crosslinked collagens after subcutaneous implantation," abstract, Transactions of the 19th Annual Meeting of the Society for Biomaterials, Birmingham, AL, April 28-May 2, 1993, p. 28.

37. P. B. van Wachem, M. J. A. van Luyn, H. K. Koerten, L. Olde Damink, H. ten Hoopen, J. Feijen, and $P$. Nieuwenhuis, "Tissue regenerating capacity of carbodiimide-crosslinked dermal sheep collagen during repair of the abdominal wall," abstract, 4th Int. Conf. BioInteractions '93, Noordwijkerhout, The Netherlands, August 29-September 1,1993 , p. 59.

Received March 19, 1993

Accepted October 15, 1993 